\title{
Demographic characteristics and complications of open and minimally invasive surgeries for renal cell carcinoma: a population-based case-control study in Taiwan
}

This article was published in the following Dove Press journal:

Therapeutics and Clinical Risk Management

\author{
Ying-Hsu Chang $1,2, *$ \\ Su-Wei Chang ${ }^{3,4, *}$ \\ Chung-Yi Liu', \\ Po-Hung Lin ${ }^{1,2}$ \\ Kai-Jie $\mathrm{Yu}^{1,2}$ \\ See-Tong Pangl,2 \\ Cheng-Keng Chuang 1,2 \\ Hung-Cheng Kan ${ }^{1,2}$ \\ I-Hung Shao ${ }^{1,2}$ \\ 'Division of Urology, Department \\ of Surgery, LinKou Chang Gung \\ Memorial Hospital, Taoyuan, Taiwan; \\ ${ }^{2}$ Graduate Institute of Clinical \\ Medical Sciences, College of Medicine, \\ Chang Gung University, Taoyuan, \\ Taiwan; ${ }^{3}$ Clinical Informatics and \\ Medical Statistics Research Center, \\ College of Medicine, Chang Gung \\ University, Taoyuan, Taiwan; ${ }^{4}$ Division \\ of Allergy, Asthma, and Rheumatology, \\ Department of Pediatrics, Chang \\ Gung Memorial Hospital at Linkou, \\ Taoyuan, Taiwan \\ *These authors contributed equally \\ to this work
}

\begin{abstract}
Introduction: Renal cell carcinoma (RCC) is one of the most lethal urological malignancies, and surgeries remain the mainstay for localized RCC. This study aimed to compare the selection of open surgery and minimally invasive kidney surgery for RCCs for the aspects of complication, medical costs, and patient preference.

Materials and methods: We conducted a population-based case-control study by using the National Health Insurance Research Database of Taiwan, which included data from 23 million Taiwanese residents. Patients newly diagnosed with RCC during 2006-2012 were included. We compared the general characteristics, underlying disease, complications, hospital stay, postoperative analgesic dosage, and medical costs between open group and minimally invasive group.

Results: A total of 3,172 patients who received radical nephrectomy $(\mathrm{RN})$ or partial nephrectomy (PN) for RCC were included. The mean age was 61.1 years, with a male to female ratio of 1.88 . In the minimally invasive groups, the mean hospital stay was significantly shorter than in open groups (12.4 days in open $\mathrm{RN}$ versus 10.3 days in minimally invasive $\mathrm{RN}$, and 9.7 days in open $\mathrm{PN}$ versus 8.2 days in minimally invasive $\mathrm{PN}$ ). There was no significant difference between the medical costs and the incidence of major bleeding complication between the open group and the minimally invasive group. Female patients and patients with higher monthly income were more likely to receive minimally invasive surgery.

Conclusion: During past decades, open RN has gradually been replaced by minimally invasive surgeries and PN. Compared to open surgeries, minimally invasive surgeries could lead to less postoperative pain and faster recovery. Economic status of the patients potentially hinders them from receiving minimally invasive surgeries, which may cost more.
\end{abstract}

Keywords: renal cell carcinoma, minimally invasive, open surgery, complication, NHIRD

\section{Introduction}

Renal cell carcinoma (RCC) is one of the most lethal urological malignancies. The 5 -year relative survival rate of RCC patients was about $71 \%$, compared to $78 \%$ for bladder urothelial cell carcinoma (excluding carcinoma in situ) and $99 \%$ for prostate cancer. ${ }^{1}$

The incidence of RCC is about 12 per 100,000 population per year, with a male to female ratio $1.5 .^{1} \mathrm{RCC}$ is a disease of aging people, with higher prevalence among those aged between 50 and 70 years. ${ }^{1-3}$ The incidence has increased in recent decades by an average of 3\%-4\% per year, and this trend was largely related to the increased prevalence of imaging survey techniques, such as ultrasonography or computed
Correspondence: I-Hung Shao Division of Urology, Department of Surgery, Chang Gung Memorial Hospital, 5 Fu-Shing Street, Kweishan, Taoyuan 333, Taiwan

Tel +8863328 I 200 ext 2103

Fax +88633285818

Email ehomeshao68@gmail.com 
tomography scan, for the evaluation of all cause of abdominal problems. ${ }^{4,5}$

With the wide use of cross-sectional imaging, RCC is more often diagnosed at early stage as localized disease. ${ }^{6-8}$ The management of localized RCC includes radical nephrectomy $(\mathrm{RN})$, partial nephrectomy $(\mathrm{PN})$, thermal ablation, and active surveillance. ${ }^{9-14}$ Among the variety of treatment modalities, surgery remains the mainstay for curative treatment of this disease.

The goal of surgery for RCC is to excise all tumors with adequate preservation of surgical margin. $\mathrm{RN}$ is the preferred option for many patients with localized RCC, such as those with very large tumors (most clinical T2 tumors) or the relatively limited subgroup of patients with clinical T1 tumors whose tumor are not amenable to nephron-sparing approaches. ${ }^{15}$ Compared to $\mathrm{RN}, \mathrm{PN}$ is the preferred choice for renal function preservation in selected feasible patients, especially for those with chronic kidney disease. ${ }^{10,15-17}$

Although effective, traditional open surgeries to the kidney are associated with significant postoperative discomfort and longer recovery period. Compared with open renal surgery, minimally invasive surgery which is laparoscopic-assisted resulted in less change in muscle volume and a lower rate of flank bulge, paresthesias, and numbness postoperatively. ${ }^{18}$

In this study, we used a nationwide health insurance database to compare the open surgery and minimally invasive kidney surgery for RCCs for the aspects of complication, medical costs, and patient preference.

\section{Materials and methods Data sources}

We conducted a population-based case-control study by using the National Health Insurance (NHI) Research Database (NHIRD) of Taiwan. The database contained data from the state-run NHI program, which was established in 1995 and provides universal health care for 23 million Taiwanese residents. ${ }^{19}$ The current health care system in Taiwan, known as NHI, was instituted in 1995. NHI is a single-payer compulsory social insurance plan which centralizes the disbursement of health care funds. The system promises equal access to health care for all citizens, and the population coverage had reached $99 \%$ by the end of 2004 . NHI is mainly financed through premiums, which are based on the payroll tax, and is supplemented with out-of-pocket payments and direct government funding. This study was approved by the Institutional Review Board of Chang-Gung Memorial Hospital (IRB), approval number 104-7905B. All patient data from NHIRD are anonymized; therefore the board did not require informed consent from the patients for this study.

\section{Study population}

In this study, patients newly diagnosed with malignant neoplasm of the kidney, except that in the pelvis (renal cancer; International Classification of Diseases, Ninth Revision, Clinical Modification [ICD-9-CM] 189.0), during the period from 2006 to 2012 were identified from the Registry for Catastrophic Illness Patient database. The insurance coverage for catastrophic illnesses is an extension of the NHI program of Taiwan for protecting people with serious diseases from the financial burden. Renal cancer is an NHI-defined catastrophic illness, and the NHI program covers the costs incurred during treatment of the disease. Patients who underwent radical or $\mathrm{PN}$ for pathologically confirmed RCC were included. Types of surgeries were as open or minimally invasive surgeries. Minimally invasive surgeries included hand-assisted/pure laparoscopic or retroperitoneoscopic surgeries.

\section{Statistical analyses}

We compared demographic characteristics, namely, gender, age, monthly income, underlying disease, and geographical location and urbanization level of the area of residence; and bleeding-related complications, hospital stay, postoperative analgesic dosage, and medical costs between the open surgery group and minimally invasive group.

Monthly income was identified according to insured amount of NHI, categorized as NTD\$20,000 (694 USD) and NTD\$40,000 NT (1,388 USD) (NTD\$ represents New Taiwan dollar). Bleeding relate complications were defined by perioperative or postoperative blood transfusion or receiving angiography with embolization during admission or 1 month after discharge from the hospital. Postoperative analgesic dosage was assessed with total postoperative dosage of opioid analgesic consumption.

The patients were then divided into 4 groups: open RN, minimally invasive $\mathrm{RN}$ (including laparoscopic and retroperitoneoscopic), open PN, and minimally invasive PN (including laparoscopic and retroperitoneoscopic). Comparison of open surgery and minimally invasive surgery was performed in $\mathrm{RN}$ and $\mathrm{PN}$ groups.

The associations between nominal variables were examined using the $\chi^{2}$ test and that between the continuous variables using independent $t$-test.

\section{Results}

A total of 3,172 patients were included, and all of them were diagnosed as having RCC and underwent either radical 
or PN for tumor excision. The mean age was 61.1 years old, with a male to female ratio of 1.88 . The mean stay in the hospital for renal surgery was 11.3 days, and medical costs was 102,186 NTD (3,546.9 USD). All the other detailed general characteristics are listed in Table 1.

The results of comparison between different surgery groups are shown in Table 2.

The percentage of open $\mathrm{RN}$, minimally invasive $\mathrm{RN}$, open PN, and minimally invasive PN are shown from 2006 to 2012 (Figure 1). The number of open $\mathrm{RN}$ performed decreased gradually, with minimally invasive $\mathrm{RN}$, open $\mathrm{PN}$, and minimally invasive PN counts increasing year by year.

The average age of patients between open $\mathrm{RN} /$ minimally invasive $\mathrm{RN}$, and open $\mathrm{PN} /$ minimally invasive $\mathrm{PN}$ was 58.9, $60.3,57.4$, and 56.9 years old, respectively. The male to female ratio was around 1.5-2.2 in all 4 groups. If $\mathrm{RN}$ or $\mathrm{PN}$ was required, the percentage of patients who received

Table I General characteristics of all patients

\begin{tabular}{|c|c|}
\hline Characteristics & \\
\hline Total patients (N) & 3,172 \\
\hline \multicolumn{2}{|l|}{ Age (years) } \\
\hline Mean & 61.1 \\
\hline$\leq 40$ & $313(9.87 \%)$ \\
\hline $4 I-50$ & 537 (I6.93\%) \\
\hline $5 I-60$ & $866(27.3 \%)$ \\
\hline $61-70$ & 720 (22.7\%) \\
\hline $7 I-80$ & $590(18.6 \%)$ \\
\hline$\geq 81$ & I 46 (4.6\%) \\
\hline \multicolumn{2}{|l|}{ Gender } \\
\hline Male & $2,070(65.26 \%)$ \\
\hline Female & I, 102 (34.74\%) \\
\hline \multicolumn{2}{|l|}{ Urbanization } \\
\hline Highly urbanized & 921 (29.04\%) \\
\hline Moderately urbanized & $1,019(32.12 \%)$ \\
\hline Emerging township & 469 (I4.79\%) \\
\hline Rural township & $483(15.23 \%)$ \\
\hline Aging township & $63(1.99 \%)$ \\
\hline Agricultural township & $120(3.78 \%)$ \\
\hline Remote area & 97 (3.06\%) \\
\hline \multicolumn{2}{|l|}{ Underlying disease } \\
\hline Hypertension & 2,205 (69.5I\%) \\
\hline Diabetes mellitus & $1,219(38.43 \%)$ \\
\hline Hyperlipidemia & I,596 (50.32\%) \\
\hline Hepatitis & $514(16.2 \%)$ \\
\hline Chronic hepatitis & $\mathrm{I}, \mathrm{I} 07$ (34.9\%) \\
\hline \multicolumn{2}{|l|}{ Monthly income } \\
\hline Dependent & $8(1.28 \%)$ \\
\hline I-I9,999 NTD (I-694 USD) & 170 (27.2\%) \\
\hline 20,000-39,999 NTD (694-I,388 USD) & $315(50.4 \%)$ \\
\hline$\geq 40,000$ NTD (>I,388 USD) & | 32 (2|. | $2 \%)$ \\
\hline Hospital stay (days), mean \pm SD & $11.3 \pm 7.9$ \\
\hline \multirow[t]{2}{*}{ Medical cost, mean \pm SD } & $102,186 \pm 81,639$ NTD \\
\hline & $(3,546.9 \pm 2,833$ USD) \\
\hline
\end{tabular}

Abbreviations: NTD, New Taiwan Dollar; USD, United States Dollar. minimally invasive surgeries among male and female groups were $23.94 \%$ and $28.13 \%$, respectively, with a significantly higher proportion of females choosing for this option ( $p=0.0104)$. In patients with monthly income more than \$NT 40,000 (1,388 USD), surgery was more likely minimally invasive when compared to patients of lower economic status.

In patients who received $\mathrm{RN}$, open group patients had significant longer hospital stay compared to those who underwent minimally invasive surgery $(12.4 \pm 8.8$ days versus $10.3 \pm 6.7$ days, $p$-value $<0.0001)$. A similar result was also seen in PN patients, with hospital stay duration of 9.7 \pm 5.7 days in open group versus $8.2 \pm 5.3$ days in minimally invasive group $(p$-value $=0.0031)$.

There was no significant difference between the medical costs when comparing open group and minimally invasive group, and neither was there a difference when comparing $\mathrm{RN}$ and $\mathrm{PN}$ groups.

In Table 3, we demonstrated the occurrence of bleedingrelated complications and opioid analgesic demand, comparing the values between the open and minimally invasive groups.

Bleeding-related complications were defined by perioperative or postoperative blood transfusion or receiving angiography with embolization during admission or 1 month after discharge from the hospital. The incidence of blood transfusion and angiography with embolization were separately listed.

In the RN group, the patients receiving open surgery had significantly higher bleeding-related complication than those in the minimally invasive group. However, there was no significant difference between patients who received open and minimally invasive PN.

The postoperative opioid analgesics demand was calculated by total dosage $(\mathrm{mg} / \mathrm{mL})$. In the $\mathrm{RN}$ group, patients receiving open surgeries significantly required more opioid analgesics than patients receiving minimally invasive surgery $(87.6 \pm 120 \mathrm{mg} / \mathrm{mL}$ versus $55.3 \pm 89 \mathrm{mg} / \mathrm{mL}$, $p$-value $<0.0001)$. However, in patients receiving $\mathrm{PN}$, open group and minimally invasive group had similar opioid analgesics demand $(49.9 \pm 65 \mathrm{mg} / \mathrm{mL}$ versus $48 \pm 65 \mathrm{mg} / \mathrm{mL}$, $p$-value $=0.8334$ ).

\section{Discussion}

For localized RCC, the efficacy and durability of operative extirpation had been demonstrated to be central to cure. However, studies also have shown that many patients can have permanent unfavorable body shape alterations with flank incisions resulting in significantly larger postoperative 


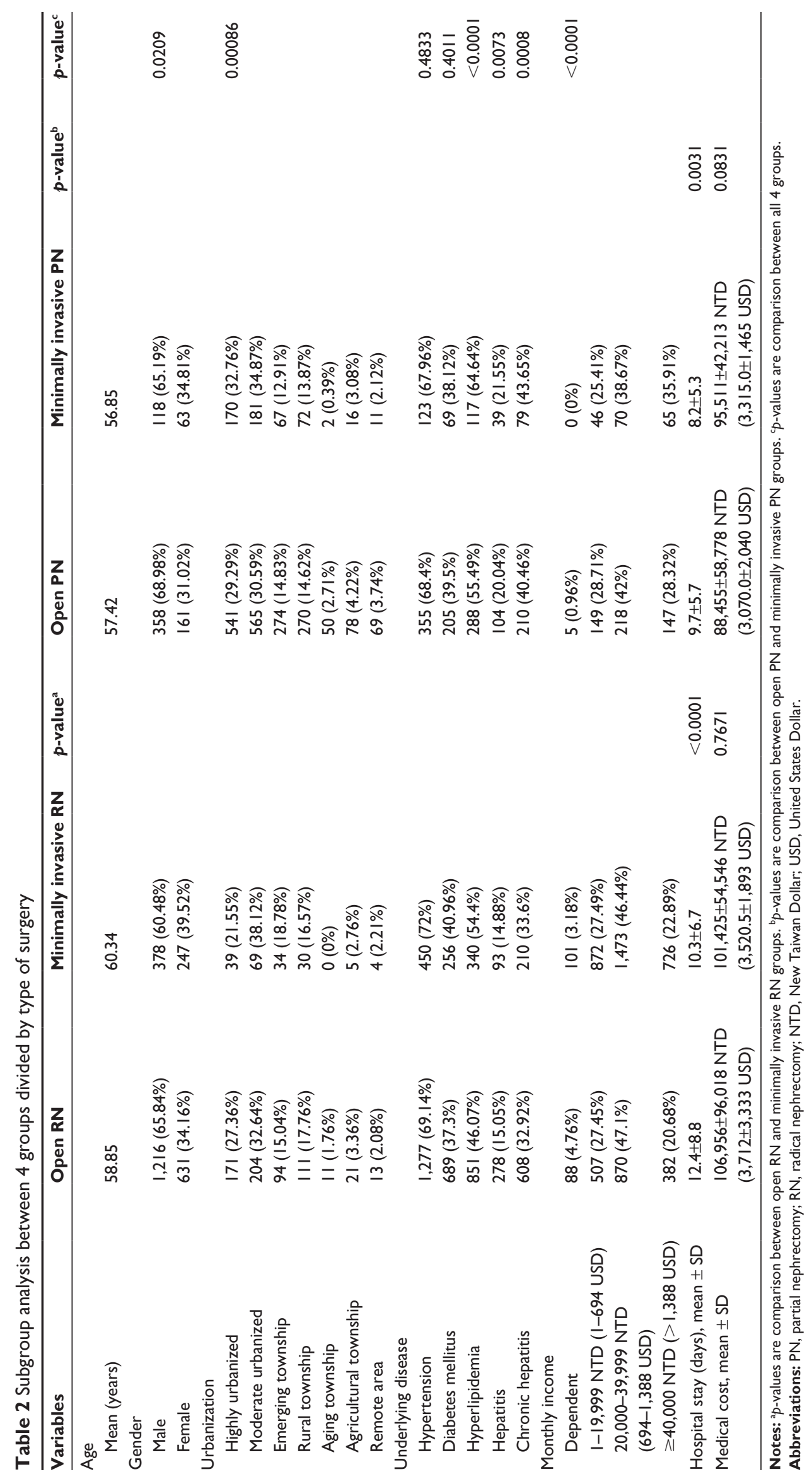




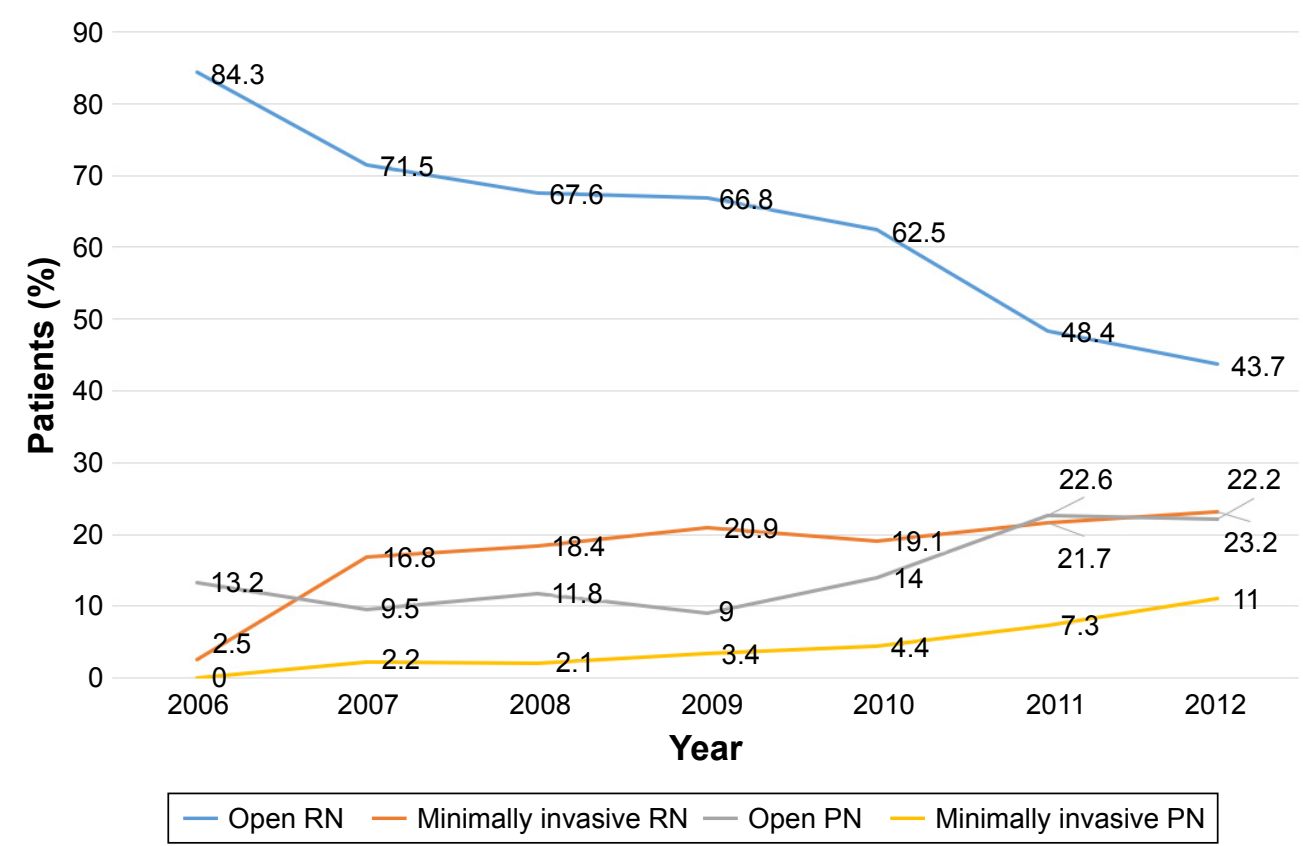

Figure I The change in the trend of surgery type for RCC in Taiwan from 2006 to 2012.

Abbreviations: PN, partial nephrectomy; RCC, renal cell carcinoma; RN, radical nephrectomy.

surface area and volume changes on the operated flank compared with the uninvolved flank. The dissatisfaction with regard to the body changes occurred in up to $60 \%$ of flank incisions, with a patient preference toward minimally invasive techniques. ${ }^{20-22}$

In addition to less body image change, minimally invasive surgery also results in minimal postoperative discomfort, a brief hospital stay, and a rapid recovery. Besides cosmetic and recovery advantage compared to open surgery, minimally invasive surgeries have been demonstrated to have equivalent functional and oncological outcomes. ${ }^{23-26}$ With experience, all manner of laparoscopic renal surgeries are now routinely accomplished without compromise on surgical outcomes.

In our study, we used a nationwide, single-payer health insurance system, which covered $99 \%$ of about 23 million
Taiwanese residents, to analyze the difference between open and minimally invasive surgeries for RCCs.

The average length of hospital stay of patients receiving minimally invasive surgeries was significantly shorter than those in the open surgery groups, with a difference of 2.1 days and 1.5 days in $\mathrm{RN}$ and $\mathrm{PN}$ group, respectively. The postoperative opioid analgesics demand was also significantly lower in open $\mathrm{RN}$ group than in minimally invasive $\mathrm{RN}$ group. This confirmed the result of previous studies regarding the faster recovery and better postoperative discomfort. ${ }^{23,27,28}$

Even with shorter hospital stay in minimally invasive group patients, the medical costs were similar in minimally invasive group and open group. However, the medical costs gathered from the Taiwan NHIRD are probably not the real total medical costs. The NHI covers most of the medical costs, except some expanse which

Table 3 Bleeding-related complications and opioid analgesics consumption in all 4 groups

\begin{tabular}{|c|c|c|c|c|c|c|c|c|}
\hline \multirow[t]{2}{*}{ Group } & \multirow{2}{*}{$\begin{array}{l}\text { Patients } \\
\text { (n) }\end{array}$} & \multicolumn{5}{|c|}{ Bleeding-related complication } & \multicolumn{2}{|c|}{ Opioid analgesics } \\
\hline & & $\begin{array}{l}\text { Either blood } \\
\text { transfusion or } \\
\text { embolization }\end{array}$ & $\begin{array}{l}\text { Blood } \\
\text { transfusion } \\
\text { only }\end{array}$ & $\begin{array}{l}\text { Embolization } \\
\text { only }\end{array}$ & $\begin{array}{l}\text { Both blood } \\
\text { transfusion and } \\
\text { embolization }\end{array}$ & $p$-value & $\begin{array}{l}\text { Total dosage } \\
(\mathrm{mg} / \mathrm{mL}), \\
\text { mean } \pm \text { SD }\end{array}$ & $p$-value \\
\hline Open RN & I,847 & $|| 6 \mid$, & $\mathrm{I}, 074(58.15 \%)$ & $15(0.81 \%)$ & $72(3.9 \%)$ & $<0.0001$ & $87.6 \pm 120$ & $<0.0001$ \\
\hline Minimally invasive RN & 625 & 297 & $282(45.12 \%)$ & $3(0.48 \%)$ & $12(1.92 \%)$ & & $55.3 \pm 89$ & \\
\hline Open PN & 519 & 234 & $210(40.46 \%)$ & II (2.I2\%) & 13 (2.5\%) & 0.394 & $49.9 \pm 65$ & 0.8334 \\
\hline Minimally invasive PN & $|8|$ & 75 & $66(36.46 \%)$ & $4(2.21 \%)$ & $5(2.76 \%)$ & & $48 \pm 65$ & \\
\hline Total & 3,172 & $\mathrm{I}, 767$ & 1,632 & 33 & 102 & & $78.9 \pm 107$ & \\
\hline
\end{tabular}

Abbreviations: PN, partial nephrectomy; RN, radical nephrectomy. 
was considered unnecessary for the treatment. Referring to laparoscopic RN or PN, medical instruments such as the GelPort Laparoscopic System manufactured by the Applied Medical Resources Corporation (Rancho Santa Margarita, CA, USA) or the Harmonic scalpel manufactured by Ethicon Endo-Surgery (Somerville, NJ, USA), etc, were considered unnecessary, although surgeons would consider those instruments helpful while performing minimally invasive renal surgeries in selected cases.

In this circumstance, a significant amount of the medical costs could be unrevealed in the study. Instead, the unrevealed medical costs were covered by the private medical insurance companies or the patients themselves. Overall, the medical expenditure paid by the patients is higher with minimally invasive surgery than with open surgery for RCC. This could also explain the trend why people with higher economic status would prefer to receive minimally invasive surgeries for RCC.

In RN group, patients receiving open surgery required more perioperative or postoperative blood transfusion than patients receiving minimally invasive surgery. However, the incidence of angiography with embolization after operation was similar in these 2 groups. The result could be explained that the overall major bleeding complications requiring angiography with embolization is similar in open surgery and minimally invasive surgeries. The benefit of cosmetic appearance and faster recovery from minimally invasive surgeries did not result in increase in major bleeding complication. However, in more advanced-stage disease, such as those with huge tumor volume, adjacent organ adhesion, or inferior vena cava thrombus, etc, open surgery was preferred to minimally invasive surgery by the surgeons, since the open surgery could possibly provide a clearer operation field and more immediate response for hemostasis if unexpected bleeding was encountered. This bias resulted in the higher chance of blood transfusion rate in open surgery group.

Despite the possible bias, this result still suggested that after proper selection of the patients, minimally invasive surgeries could provide adequate safety for hemostasis and no more bleeding complication than open surgeries.

Although many studies have demonstrated advantage of minimally invasive surgery for kidney cancers, as mentioned earlier, the minimally invasive surgeries including laparoscopic and retroperitoneoscopic surgeries have been underutilized. ${ }^{29-31}$

It is thought that after controlling all the variables including demographics, tumor size, and comorbidities, the consideration and preference of surgeons were the most significant predictors for the type of surgery performed.
Besides the preference of surgeons, in this study we also addressed the possible impact of patients' economic status on the choice of medical treatment modalities, as some require extra expenditure. Also, female patients were more likely to choose minimally invasive surgeries if $\mathrm{RN}$ or $\mathrm{PN}$ is required. Cosmetic preference might be one of the reasons for this.

There has been a noticeable trend toward increased application of PN, both open and laparoscopic, and a trend toward minimally invasive renal surgeries such as laparoscopic and robotic-assisted laparoscopic over time. ${ }^{32}$ Our results also revealed a trend of decreased open $\mathrm{RN}$, and instead increased minimally invasive $\mathrm{RN}$ and both open and minimally invasive PN during 2006-2012.

Although the open surgery still played an important role in managing certain complicated cases, the rapid and wide adoption of minimally invasive techniques for kidney surgeries in selected and suitable candidates is occurring. In addition, the incorporation of robotic assistance in minimally invasive renal surgery may also facilitate broader implementation of minimally invasive renal surgery. ${ }^{33}$

\section{Conclusion}

During past decades, fewer and fewer open radical nephrectomies were performed in patients with $\mathrm{RCC}$ requiring surgery in Taiwan. Instead, the number of cases of minimally invasive surgeries and PN increased. Compared to open surgeries, minimally invasive surgeries could lead to less postoperative pain and faster recovery. The economic status of the patients potentially hinders them from receiving minimally invasive surgeries which may cause more medical costs.

\section{Acknowledgment}

The authors acknowledge institutional grants from the Research Services Center for Health Information, Chang Gung University, Taoyuan, Taiwan (CMRP-MK 103 number: CIRPD1D0031/CMRP-MK 104 number: CIRPD1D0032).

\section{Disclosure}

The authors report no conflicts of interest in this work.

\section{References}

1. Siegel R, Naishadham D, Jemal A. Cancer statistics, 2013. CA Cancer J Clin. 2013;63(1):11-30.

2. Pantuck AJ, Zisman A, Belldegrun AS. The changing natural history of renal cell carcinoma. J Urol. 2001;166(5):1611-1623.

3. Wallen EM, Pruthi RS, Joyce GF, Wise M; Urologic Diseases in America Project. Kidney cancer. J Urol. 2007;177(6):2006-2018; discussion 2018-2019. 
4. Decastro GJ, McKiernan JM. Epidemiology, clinical staging, and presentation of renal cell carcinoma. Urol Clin North Am. 2008;35(4): 581-592; vi.

5. Kummerlin IP, ten Kate FJ, Wijkstra H, de la Rosette JJ, Laguna MP. Changes in the stage and surgical management of renal tumours during 1995-2005: an analysis of the Dutch national histopathology registry. BJU Int. 2008;102(8):946-951.

6. Lipworth L, Tarone RE, McLaughlin JK. The epidemiology of renal cell carcinoma. J Urol. 2006;176(6 Pt 1):2353-2358.

7. Jemal A, Bray F, Center MM, Ferlay J, Ward E, Forman D. Global cancer statistics. CA Cancer J Clin. 2011;61(2):69-90.

8. Miller DC, Ruterbusch J, Colt JS, et al. Contemporary clinical epidemiology of renal cell carcinoma: insight from a population based casecontrol study. J Urol. 2010;184(6):2254-2258.

9. Kunkle DA, Egleston BL, Uzzo RG. Excise, ablate or observe: the small renal mass dilemma - a meta-analysis and review. J Urol. 2008;179(4):1227-1233; discussion 1233-1224.

10. Campbell SC, Novick AC, Belldegrun A, et al. Guideline for management of the clinical T1 renal mass. J Urol. 2009;182(4):1271-1279.

11. Aron M, Kamoi K, Remer E, Berger A, Desai M, Gill I. Laparoscopic renal cryoablation: 8-year, single surgeon outcomes. J Urol. 2010; 183(3):889-895

12. Van Poppel H, Becker F, Cadeddu JA, et al. Treatment of localised renal cell carcinoma. Eur Urol. 2011;60(4):662-672.

13. Volpe A, Cadeddu JA, Cestari A, et al. Contemporary management of small renal masses. Eur Urol. 2011;60(3):501-515.

14. Kim SP, Thompson RH. Approach to the small renal mass: to treat or not to treat. Urol Clin North Am. 2012;39(2):171-179.

15. Nguyen CT, Campbell SC, Novick AC. Choice of operation for clinically localized renal tumor. Urol Clin North Am. 2008;35(4): 645-655; vii.

16. Nakada SY. Surgical removal of small renal tumors - going, going, gone? J Urol. 2005;174(1):9.

17. Russo P, Huang W. The medical and oncological rationale for partial nephrectomy for the treatment of T1 renal cortical tumors. Urol Clin North Am. 2008;35(4):635-643; vii.

18. Crouzet S, Chopra S, Tsai S, et al. Flank muscle volume changes after open and laparoscopic partial nephrectomy. J Endourol. 2014;28(10): 1202-1207.

19. Lu JF, Hsiao WC. Does universal health insurance make health care unaffordable? Lessons from Taiwan. Health Aff (Millwood). 2003; 22(3):77-88.

20. Chatterjee S, Nam R, Fleshner N, Klotz L. Permanent flank bulge is a consequence of flank incision for radical nephrectomy in one half of patients. Urol Oncol. 2004;22(1):36-39.
21. Kobayashi T, Terai A, Yoshimura K, Nishizawa K, Mitsumori K, Ogura K. Assessment of body image alteration after renal surgery using a novel three-dimensional laser scanner. Urology. 2004;64(2):264-268.

22. Park SK, Olweny EO, Best SL, Tracy CR, Mir SA, Cadeddu JA. Patient-reported body image and cosmesis outcomes following kidney surgery: comparison of laparoendoscopic single-site, laparoscopic, and open surgery. Eur Urol. 2011;60(5):1097-1104.

23. Kerbl K, Clayman RV, McDougall EM, Kavoussi LR. Laparoscopic nephrectomy: the Washington University experience. Br J Urol. 1994; 73(3):231-236.

24. Dunn MD, Portis AJ, Shalhav AL, et al. Laparoscopic versus open radical nephrectomy: a 9-year experience. J Urol. 2000;164(4):1153-1159.

25. Gill IS, Kavoussi LR, Lane BR, et al. Comparison of 1,800 laparoscopic and open partial nephrectomies for single renal tumors. J Urol. 2007;178(1):41-46.

26. Tan HJ, Wolf JS Jr, Ye Z, Wei JT, Miller DC. Population-level comparative effectiveness of laparoscopic versus open radical nephrectomy for patients with kidney cancer. Cancer. 2011;117(18):4184-4193.

27. Golombos DM, Chughtai B, Trinh QD, et al. Minimally invasive vs open nephrectomy in the modern era: does approach matter? World $J$ Urol. 2017;35(10):1557-1568.

28. Bayrak O, Seckiner I, Erturhan S, Cil G, Erbagci A, Yagci F. Comparison of the complications and the cost of open and laparoscopic radical nephrectomy in renal tumors larger than 7 centimeters. Urol J. 2014;11(1): 1222-1227.

29. Permpongkosol S, Bagga HS, Romero FR, Solomon SB, Kavoussi LR. Trends in the operative management of renal tumors over a 14-year period. BJU Int. 2006;98(4):751-755.

30. Miller DC, Saigal CS, Banerjee M, Hanley J, Litwin MS; Urologic Diseases in America Project. Diffusion of surgical innovation among patients with kidney cancer. Cancer. 2008;112(8):1708-1717.

31. Liu JJ, Leppert JT, Maxwell BG, Panousis P, Chung BI. Trends and perioperative outcomes for laparoscopic and robotic nephrectomy using the National Surgical Quality Improvement Program (NSQIP) database. Urol Oncol. 2014;32(4):473-479.

32. Poon SA, Silberstein JL, Chen LY, Ehdaie B, Kim PH, Russo P. Trends in partial and radical nephrectomy: an analysis of case logs from certifying urologists. J Urol. 2013;190(2):464-469.

33. Patel HD, Mullins JK, Pierorazio PM, et al. Trends in renal surgery: robotic technology is associated with increased use of partial nephrectomy. J Urol. 2013;189(4):1229-1235.
Therapeutics and Clinical Risk Management

\section{Publish your work in this journal}

Therapeutics and Clinical Risk Management is an international, peerreviewed journal of clinical therapeutics and risk management, focusing on concise rapid reporting of clinical studies in all therapeutic areas, outcomes, safety, and programs for the effective, safe, and sustained use of medicines. This journal is indexed on PubMed Central, CAS,

\section{Dovepress}

EMBase, Scopus and the Elsevier Bibliographic databases. The manuscript management system is completely online and includes a very quick and fair peer-review system, which is all easy to use. Visit $\mathrm{http}: / / \mathrm{ww}$.dovepress.com/testimonials.php to read real quotes from published authors. 